\title{
ANALYSIS OF IMMUNE GENE EXPRESSION IN ROCK BREAM SPLEEN AFTER ROCK BREAM IRIDOVIRUS INFECTION BY TRANSCRIPTOME SEQUENCING
}

\author{
Jae-Heon Park ${ }^{1}$, Hyun Do Jeong ${ }^{2}$, Suhee Hong ${ }^{1 \S}$ \\ ${ }^{1}$ Department of Marine Biotechnology, Gangneung-Wonju National University \\ ${ }^{2}$ Department of Aquatic Life Medicine, Pukyong National University
}

\begin{abstract}
Rock bream (Oplegnathus fasciatus) aquaculture in Korea has been threatened by Rock bream iridovirus (RBIV), a megalocytivirus widely infected in various fish species. Major symptoms of RBIV infection is acute inflammation and enlargement of spleen. There is no available vaccine for RBIV though closely related red sea bream irido virus has been successfully prevented by a commercial vaccine. Without any effective vaccine for RBIV, it has been causing a huge economic loss in rock bream aquaculture industry in Korea. In this study, differential immune gene expression in spleen of rock bream was assessed by sequencing of whole transcriptome to understand rock bream immune system under RBIV infection at day 4 . As a result, 402,848 contigs were obtained after de novo assembly and the fold change was counted for each contigs in infected versus noninfected fish. 96,015 contigs showed differential expression as fold change was higher or lower than 2. Among the differentially expressed contigs, immune related genes like interferon-induced protein 44 showed the fold change of 1582.5 while Fc receptor-like protein 5 showed the fold change of 83.8. IL-1 $\beta$, lamda chain of immunoglobulin (Ig) and Ig alpha chain were down-regulated, while interleukin-10, perforin-1 and inhibitor of nuclear factor kappa-b kinase $\varepsilon$ were upregulated at day 4 post RBIV infection. Interestingly, proteins in complement system (C1 to C9 (no C4), factor B) were upregulated but complement factor $\mathrm{H}$ (a regulator of complement system) was down-regulated, revealing the activation of alternative pathway. Differentially expressed genes were confirmed by Q-PCR and the expression was analysed in vitro and in vivo.
\end{abstract}

\section{KEYWORDS}

Rock bream (Oplegnathus fasciatus), RBIV, spleen, RNA seq,

${ }^{\S}$ Corresponding author. Tel.: +82 33640 2852; Fax: +82 336402955.

E-mail address: s.hong@gwnu.ac.kr 